\title{
Using social media to create a participatory library service: an Australian study
}

\author{
Kathleen Smeaton, Kate Davis
}

\begin{abstract}
Public libraries are increasingly using social media in an attempt to meet users in their own spaces. Social media can be useful when used to create a participatory library service emphasising engagement with users. However, there has been little empirical investigation into the success of social media use by public libraries. This article reports on the findings of a research project that explored the use of social media by Australian public libraries.
\end{abstract}

Two organisations participated in case studies that involved interviews, document analysis, and social media observation. To contextualise the use of social media in the case study organisations, a sub-study was undertaken involving observation of an additional 24 public libraries across Australia. This article focuses on the findings from the observation sub-study. It presents and applies a methodology for classifying social media content to determine whether the sample libraries' social media use is indicative of a participatory approach to service delivery.

This article explores how a range of social media platforms are used by the sample libraries and considers what best practice in participatory library service looks like. The two case study organisations' use of social media is highlighted as exemplary practice.

\section{Introduction}

The concept of the participatory library suggests that the library should engage in conversations with its community and that these conversations should inform how the library operates (Lankes, 2011). Many libraries have accepted that social

\section{Author}

Kathleen Smeaton is an Advanced Masters Student at Queensland University of Technology in the Master of Information Technology (Library and Information Studies).

Email: kathleen.smeaton@connect.qut.edu.au

Kate Davis is a Transformation Fellow / Lecturer in Information Systems at Queensland University of Technology. 
media can help them to achieve their mission of engaging with the community, and specifically, allowing them to participate in conversation with their community (Rutherford, 2008a, 419). For the purposes of this study, social media can be broadly defined as tools that provide opportunities for customers to engage with content produced by the library, including tools such as Twitter, Facebook and blogs.

This need for libraries to participate in conversation is based upon Lankes' (2011) idea of a participatory library, a library in the business of conversation as it is conversations which create knowledge. This can be viewed clearly by examining what it is that libraries do:

The concept of learning through conversation is evidenced in libraries in such large initiatives such as information literacy and teaching critical thinking skills.... and in the smaller events of book groups, reference interviews, and speaker services. Library activities such as building collections of artefacts (the tangible products of conversation) inform scholars' research through a formal conversation process where ideas are supported with evidence and methods.

(Lankes, Silverstein and Nicholson, 2007, 18)

By having conversational channels that are always open and participating in dialogue with users, the library is able to constantly evaluate and refine its programs, products and services to ensure that the users are getting what they need (Casey and Savastinuk, 2006). In a time when the relevance of the library is being questioned, this approach can help libraries to remain relevant. Social networking can no longer be seen as a passing fad; these Web 2.0 technologies are now the benchmark of a successful service as users expect to be able to interact with, and become co-creators of, content (Breeding, 2010).

It is important that libraries act to take advantage of this and invite participation, with active rather than passive participation being the goal (Porter and King, 2007). Passive participation is when the library provides excellent content and simply asks the user to comment, while active participation involves the library inviting its users to create a community with the library and to help in shaping its direction, co-authoring content and engaging with other users to form a vocal community of users (Porter and King, 2007).

While libraries have been quick to take up social media technologies, creating blogs, Facebook pages, Twitter accounts and more, there has been little exploration of how successful these technologies have been in meeting library aims and whether social media is being used to drive a participatory service.

This paper reports on the findings from a social media monitoring observation activity that formed part of a larger research project. The broader project focused on exploring how Australian public libraries use social media to create participatory libraries. In particular, the objective of this study was to contribute to the understanding of best practice for using social media to connect with communities.

This article presents an analysis of the observation data in context of the key themes identified in the literature review. First, the article identifies the key 
themes from the literature related to public libraries' use of social media with a particular focus on use of social media to design and deliver participatory services. Next, it proposes a classification system that can be applied to public library social media content to allow libraries to consider critically how they use social media to engage their users in conversation. Examining each social media platform in turn, the article discusses how the platforms are being used by public libraries as well as the best practice usage of each tool and innovative examples of use by public libraries. Best practices presented here have been published separately (Smeaton and Davis, 2014) but were derived from the interactions observed on social media, the use of these tools to create a participatory service combined with case study interviews of Yarra Plenty Regional Library (YPRL) and City Libraries Townsville (CLT). The findings presented in this article will allow public libraries to consider which platforms they can use, and the type of messages to post, to start a conversation with their users and move towards a participatory service.

\section{Literature review}

\subsection{Public libraries}

Public libraries have always filled a number of roles in the community: information repositories and providers, as well as education and social advocates, with their roles changing as the communities that they serve evolve (Berot and McClure, 2008; Norman, 2012). The mission of public libraries, as defined by ALIA, is to offer free access to information, support formal and informal learning, provide a space for the community to gather and allow access to technology (ALIA, 2010). The provision of public internet access has allowed public libraries to play a role in creating an informed citizenry and it is often cited as a primary reason for its continued existence (Norman, 2012; Waller, 2008; McShane, 2011; Bertot and McClure, 2008; Prentice, 2010).

Public libraries have always curated collections that reflect their users and their location, holding both fiction and local history collections. There is a call for public libraries to move further into this space and start to collect, curate and store online community knowledge, building on the idea of public libraries as the third or public place, where communities can gather to discuss and debate ideas and create content that aids in the creation and continuation of society (RooneyBrowne and McMenemy, 2010; Waller, 2008; Norman, 2012). This idea would also see libraries expand their facilities to include maker spaces and online spaces to facilitate this (Norman, 2012; Manness, 2006).

Norman $(2012,97)$ tells us that for public libraries to survive they need to recognise their changing role which "is shifting to that of content aggregators, access managers and educators in digital literacy". It is easy to see how social media can help the library in these roles, allowing the library to form closer bonds with the community which it can build upon to fulfil its changing mission.

\subsection{The participatory library}

In all the scenarios that imagine the public library of the future, user participation is always at the heart of the service (Nguyen, Partridge and Edwards, 2012). The 
idea of a participatory library builds on definitions of Fitcher (2006) who defined Library 2.0 as "Library $2.0=$ (books $n$ stuff $\mid$ people $\mid$ radical trust $) \mathrm{x}$ participation". The participatory library system is a library that embraces openness and allows users to help to develop library services that are useful to them, creating a library which has users at its core and remains relevant (Nguyen et al., 2012). While libraries have traditionally been user focused, the participatory library expands on the radical trust in Fitcher's definition and gives the users more ability to guide the direction of the library service (Nguyen et al., 2012).

\subsection{Creating a participatory library}

The public library of the future involves close contact between the library and its users. This participatory library is one engaged in conversation with users. By engaging in conversation with users, the library develops knowledge about them that can inform development and delivery of services and collections (Lankes et al., 2007, 18).

This conversational idea also supports the notion of user-driven change which is often cited as one of the core principles of the future library (Casey and Savastinuk, 2006). Social technologies can support the key ideas that underpin the idea of a participatory library service: user-centred change; participation from users in developing service; and continual re-evaluation of services (Casey and Savastinuk, 2006).

Social media also allows the library to enter into the space of the user, rather than waiting for the user to come to them. The library then begins actively seeking out conversations and participation and is able to speak with people it may otherwise not reach (Lankes et. al, 2007). The information and feedback that users provide is the "single best tool" (Cahill, 2009, 47) that public libraries have to ensure that they remain relevant. If the key role of the librarian is to "improve society through facilitating knowledge creation in their communities" (Lankes, 2011, 15), then librarians must come to understand that a participatory environment is key to facilitating knowledge creation. Social media provides a ready-made communication channel that the library can use to create user engagement and move towards a participatory service (Fernandez, 2009). The question is: how are libraries using social media to create participatory networks that foster knowledge? (Lankes et al., 2007).

\subsection{Relationship between library and user}

Libraries have always invited user participation and social media can be seen as simply a new way for users to interact with their library (Porter and King, 2007). In Fitcher's definition of Library 2.0, each element in the mix is important, but perhaps one of the most difficult to embrace is "radical trust". Stephens (2007) argues that, while libraries may have the people and resources, there is still a need to deal with the trust and participation issues raised by social media. Social media allow users to be involved with the library in a completely new way, giving them more power in decision-making and content creation and some librarians are uncomfortable with this (Joint, 2010). 
While social media can be seen quite clearly to fit in with the mission of public libraries, there will still be staff that are resistant to its use (Casey and Savastinuk, 2007). However, it is increasingly necessary for staff to view their roles as facilitators of shared knowledge rather than the experts, and this will mean a change in staff mindsets and attitudes (Cahill, 2009). Social media can assist with this.

There needs to be a shift in thinking that positions users and library staff as collaborators and co-creators. There is immense value in harnessing user knowledge through practices like facilitating tagging or commenting on a resource they have used, and in many instances, user knowledge is superior to librarian knowledge (Cahill, 2009). Users have a great deal to offer, from descriptive tagging of content to providing reading advice or reviews. However, some library staff feel that these practices hand control to the users and this can be threatening. Staff may feel it is their job to provide these services and that co-creation means users are effectively doing the librarian's job. Research suggests, though, that allowing users to help describe resources and to create content, the library can stay relevant (Tarulli, 2012). Library staff and customers must become collaborators.

If social media is to be truly transformational within the library environment, the library needs to relinquish control and allow users to be participants in the organisation (Joint, 2010). The relationship between users and libraries is changing in ways that some may see as threatening the long established status quo, where the librarian operated from a position of authority. This challenge is understandably one that many library staff struggle with. Public libraries are facing challenges relating to meeting diverse client needs and remaining relevant to all users (ALIA, 2010). Thoughtful use of social media can break down barriers between librarians and users, help create services that better serve users by creating a new kind of relationship between staff and users (Joint, 2010).

\subsection{Summary}

Social media is about communication, conversation and participation, as is the participatory library. Social media is not a shiny toy, nor is it a specialist IT skillset. Rather, it is a set of tools that can assist to build a community with library users (King and Willen Brown, 2009). Social media supports the traditional goal of the library - connecting people with information - in new ways. Users have different expectations today to ten or even five years ago. They now expect to be able to contact and engage with organisations of all types in their preferred social media channels (Chase, 2007; Kwanya, Stillwell and Underwood, 2009). That many libraries have been quick to take up social media illustrates acceptance of this idea. Yet there is a concern in the literature that libraries have lost sight of the fact that Web 2.0 technologies are tools that can help achieve objectives, not objectives in themselves (Nguyen, Partridge and Edwards, 2012). The goal in deploying social media for service delivery is the creation of a library service that is seen as increasingly valuable by the public (Nguyen et al., 2012). 


\section{Methodology}

This article reports on the findings of a social media observation activity that formed part of a larger study. The methodology of the larger study is discussed briefly here, and the observation activity is discussed in detail.

The objective of this study was to contribute to the understanding of best practice for using social media in public libraries to connect with communities. This paper focuses on four research questions:

1. How are libraries using social media (information disseminators or participatory network)?

2. What are they hoping to achieve through the use of social media?

3. What is the impact?

4. How does using social media support stated goals and missions?

The larger study also approached two additional questions:

- What are the challenges and benefits?

- How does the organisational culture of a workplace affect the use of these tools?

These two research questions are not addressed in this article.

The project involved case studies of social media use in two Australian public library services. YPRL is a library service that operates in the northern suburbs of Melbourne, in the state of Victoria, comprising eight branch libraries and two mobile libraries servicing a population of 352,198 (Yarra Plenty Regional Library, 2012). YPRL is a library corporation, governed by a library board consisting of two councillors from each of the municipalities it serves and the Library CEO. CLT is a Queensland library service which operates in the city of Townsville, consisting of three branch libraries and a mobile library servicing a population of 180, 389 (Townsville City Council, 2010). CLT operates as a division of Townsville City Council.

The case studies involved document analysis of policies and procedures as well as interview with staff and senior management. Observation of both organisations' social media activity was undertaken for a ten-week period.

During the literature review and the initial stages of the observation of the two case study organisations, it became clear that there was little empirically derived research that could be used to contextualise the practice of the two case study organisations. To provide context, an additional 24 public libraries were added to the observation.

These additional libraries were selected randomly on a state-by-state basis. The number of libraries examined per state correlated to population size; that is, the higher the population of the state, the more libraries were selected.

Of the 24 other libraries that were selected for observation only one had no presence on any social media platform. The remaining libraries had a presence on at least one channel, even if their account was not active during observation. In 
some cases, library interactions took place under a generic governing body account, such as a whole of Council Facebook page. Prior to commencement of the observation, these generic accounts were checked for mentions of the library, and where the library had been mentioned in the content, these accounts were also monitored. However, only interactions relating to the library were recorded as part of the observation.

Observation was undertaken across the major social media platforms in use by Australian public libraries: Facebook, Twitter, blogs, YouTube, Flickr and Pinterest. The two case study organisations were observed for ten weeks. The observation of the additional 24 libraries commenced later, and lasted for six weeks. Observation of the social media accounts was carried out daily by the researcher. Each account was checked daily for new content, and content that had previously been posted was checked to ascertain whether it had generated any comments or responses.

To understand whether public libraries were using social media to generate conversation, moving towards a participatory service, it was necessary to categorise each interaction, not just recording the number of times a social media account was used as has been the case in previous studies (Stuart, 2010). While the number of times an account is used gives insight into the commitment of the library in using social media, more information was needed for this study.

Although there has been much discussion of the use of social media in the literature, there has been little empirical research undertaken related to library practice. Therefore the researchers devised categories based on ideas relating to engaging with customers over social media, to add value for a service as opposed to using social media as an advertising space, which has limited value (Cahill, 2009; Rutherford, 2008a; King, 2012).

In the initial analysis, the observational data statistics were collated and sorted into the four categories devised by the researchers for interactions that took place over Twitter, Facebook, blogs, and YouTube: broadcast, information sharing, information sharing to engagement or engagement. Using these four categories meant that the researchers could clearly analyse the intent of the message, rather than focusing on the content.

\subsection{Broadcast}

The purpose of a broadcast message is to encourage use of a service, resource or attendance at an event (Figure 1). These messages are a good way to raise the library's profile and create a library personality (Cahill, 2011; Fitcher, 2007; King, 2011). Social media is inherently interactive, encouraging conversation and collaboration. Libraries that focus on broadcasting messages will not realise the full potential of social media and may even turn users away (Gunton and Davis, 2012; Lankes et al., 2007).

\subsection{Information sharing}

Information sharing interactions (Figure 2) are a key use of social media for libraries (King, 2012) and typically consist of two types of messages: 
- Messages containing information that did not directly relate to library services resources or events.

- Messages that focus on the library but are not simply marketing messages. Rather they are focused on creating an image or personality for the library on creating a persona with which users want to engage (King, 2012). For example, images of a past library event, a meme, a book review, or a postcard from a staff member on holiday.

\section{SEARCHING FOR FUN. \\ Posted on Friday, November 30, 2012 - 13:54}

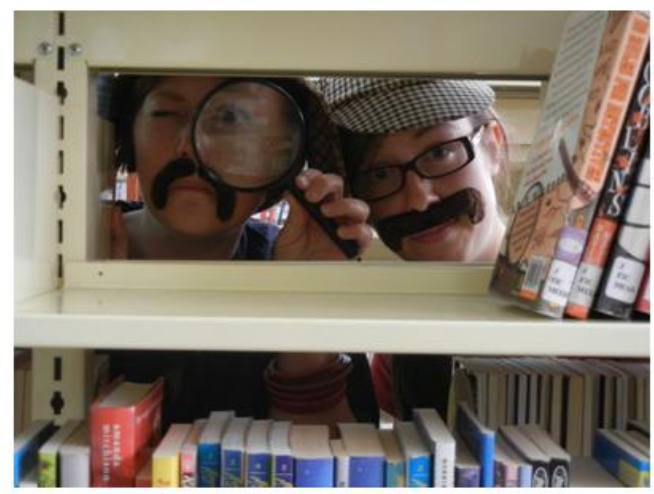

Haven't a clue how to have fun this summer? We have the answer you have been searching for.

The Summer Reading Club is being launched with great seriousness and some fake facial hair at the Mill Park Library

Monday 3rd December 4-5pm.

Figure 1: An example of a broadcast message, a blog post advertising a library event but doing so in a way that shows personality.

@TownsvilleLib: Are you one of the $55.4 \%$ who always carry a romance novel? Results of @ARRAinc survey available now http://t.co/nRPt2Jjo \#tsvreads \#nyr12 -a

Figure 2: An example of an information sharing tweet.

\subsection{Information sharing to engagement}

While information sharing messages serve a valid purpose, it is preferable if users find the information being shared of enough interest to then interact, making the library account worth following (King, 2012). Where customers responded to an information sharing post, it was coded as information sharing to engagement (Figure 3). 


\subsection{Engagement}

The engagement category (Figure 4) describes content that seeks to engage users, to encourage them to interact or participate in a conversation. Engagement messages are not necessarily about the library, its services or collections. Conversations around library services are obviously beneficial but those around other topics encourage community and participation (King and Willen Brown, 2009). For example a question about users' recommended holiday reads can help create a feeling of community amongst library users, encourage users to generate content, and facilitate participation (as long as the library remains engaged in the conversation) (King, 2012).

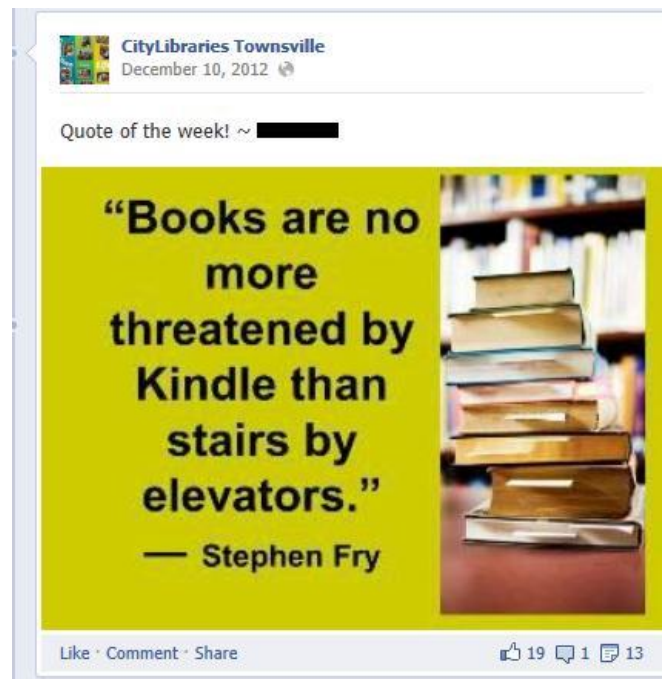

Figure 3: An example of an information sharing to engagement message, a Facebook post that shares a photo and then generates discussion (not included in order to protect user privacy).

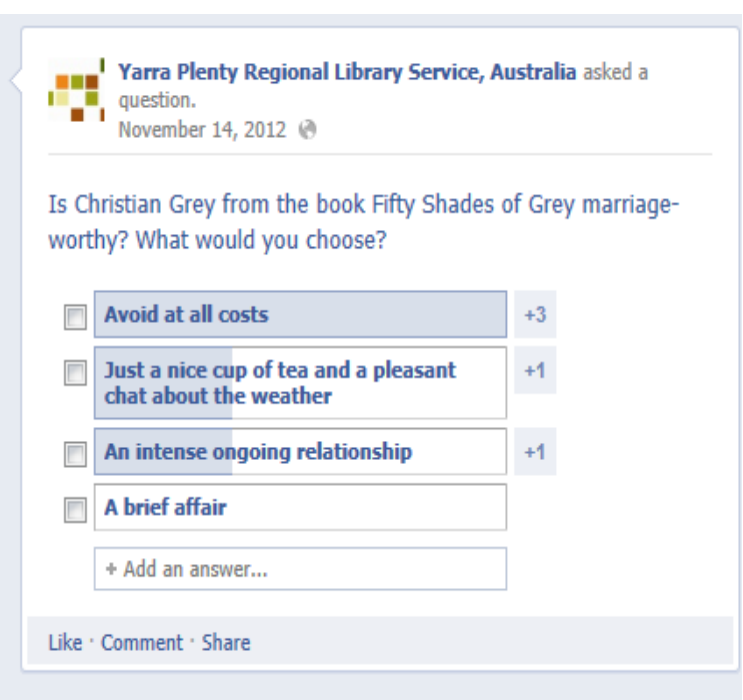

Figure 4: An example of an engagement message, a survey which creates an engaging personality for the library. 


\subsection{Average use}

The average number of interactions per day was calculated using a method based on Stuart (2010): the total number of updates was divided by the number of days monitored. As Stuart (2010) acknowledges, this average can be skewed as it may include interactions with a single customer and does not take into account the way social media can be used by libraries, with a flurry of activity across one or two days, then no interaction for long periods. However, this method does still allow for the development of a big picture of social media use by libraries, as the average provides a broad overview of library usage of each tool over the observation period.

\subsection{Pinterest and Flickr}

Pinterest and Flickr, as image sharing sites, are used in different ways to the other social media sites. Images that are uploaded need to grab attention quickly without explanatory text. There is also less ability to pose questions to customers so engaging them occurs through posting an image that creates interest. This meant that a different method of analysis was needed for each tool.

Many of the images that are uploaded to Flickr can be classified as information sharing so a broader approach was taken. Firstly, the amount of times that a library service used Flickr to upload photos was analysed. Then the uploaded images were counted. For example, the service may have only used Flickr once in the monitoring period, but uploaded 25 images. The images and account were then analysed to determine the purpose of the account. Flickr connections were analysed to see which groups libraries were interacting with to ascertain whether their Flickr use was of benefit to developing their community profile and connections.

Pinterest's premise is that pinning interesting images gathers followers. The images that are seen as interesting are then re-pinned and shared amongst the Pinterest community which can lead users back to the library board. One way to create a unique and appealing board is to create a visual collection, whether this is library resources or other relevant subjects. The collection of images that each library service had pinned was examined to determine the concept behind their collection. This was then related back to their number of followers and also their number of pins, as the more activity and interesting images pinned would impact on their followers.

\section{Findings}

\subsection{Facebook}

Facebook is the most popular social networking site in Australia (Cowling, 2013). Facebook's popularity and reach make it an ideal place to connect with users. Indeed libraries are seeking to capitalise on this with Facebook being used by more of the observed libraries than any other platform. Of the 26 libraries observed, 22 (including YPRL and CLT) have Facebook accounts. It is recommended that libraries post once per day (King, 2011) and most posted below this rate (Table 1). 


\begin{tabular}{|l|l|l|l|l|}
\hline Library & Average posts & & Library & Average posts \\
\hline Lib m & 2.1 & & Lib c & 0.24 \\
\hline CLT & 1.3 & & Lib a & 0.18 \\
\hline Lib e & 1.2 & Lib g & 0.18 \\
\hline Lib h & 1 & Lib v & 0.1 \\
\hline Lib i & 1 & Lib j & 0.07 \\
\hline Lib n & 0.9 & Lib l & 0.04 \\
\hline YPRL & 0.8 & Lib s & 0.04 \\
\hline Lib t & 0.7 & Lib x & 0.02 \\
\hline Lib w & 0.6 & Lib p & 0 \\
\hline Lib d & 0.57 & Lib r & 0 \\
\hline Lib f & 0.27 & Lib u & 0 \\
\hline Table 1: Average & & & \\
\hline
\end{tabular}

\section{Table 1: Average Facebook posts per day.}

The type of post is more important than the number of posts. To get the full benefit from Facebook, libraries should keep their Facebook pages informal, constantly updated, unique, innovative, and provide a space for discussion (Tagtmeier, 2010; King, 2011). These practices, however, are not ingrained in the libraries observed. The types of messages that were posted are analysed below.

\section{Broadcast}

YPRL and CLT posted very few broadcast messages, a trend which was reflected across the other libraries monitored. This is encouraging, especially when compared with some of the data collected in the US, which has reported much higher rates of broadcast messages (Aharony, 2012). This may indicate that Australian libraries are starting to use Facebook in a more effective way to engage users as well as promoting their services.

\section{Information sharing / Information sharing to engagement}

Well over a third of YPRL and CLT's posts fell into the information sharing to engagement category and they had a very low rate of pure information sharing posts. 

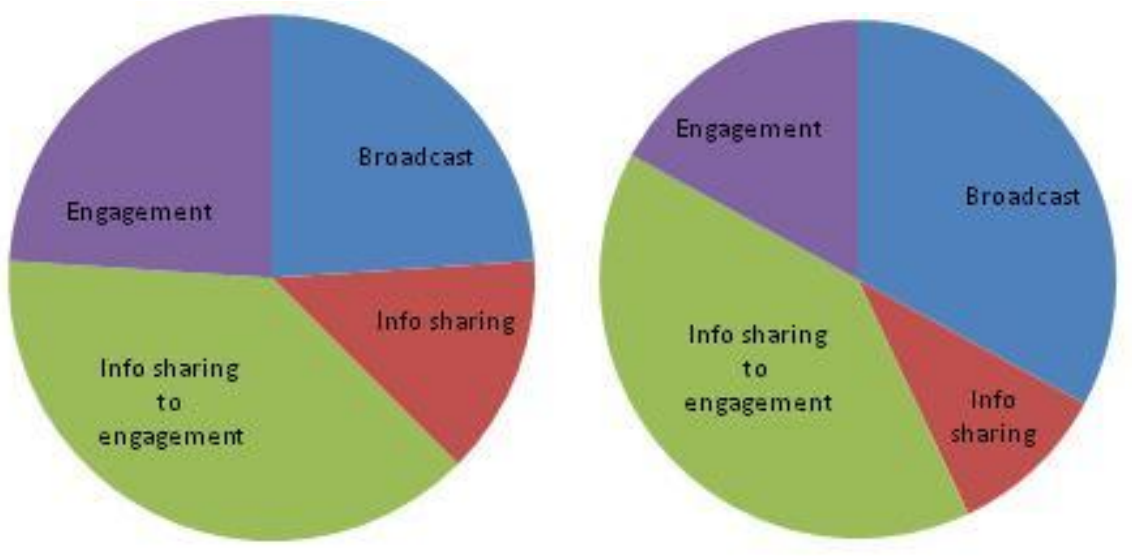

Figure 5: Charts showing post type proportions for YPRL (left) and CLT (right).

If the point of social media is to engage and facilitate conversation, ideally every post would garner a response. Both YPRL and CLT's low rates of pure information sharing posts demonstrate that they are posting information they know appeals to their users, thus generating a high rates of interaction. This indicates that they are finding the right voice to connect with users. Only three other libraries had achieved a similar level of engagement.

\section{Engagement}

The proportion of messages that were pure engagement was also quite high across the libraries monitored. However, some libraries with high engagement post levels, posted very infrequently, which resulted in them having very few "likes" and site traffic as users did not engage with a presence that was not maintained. This is in contrast to YPRL and CLT (Figure 6) who were posting engagement messages around $20 \%$ of the time and who posted frequently enough to create a follow-worthy account and get responses.

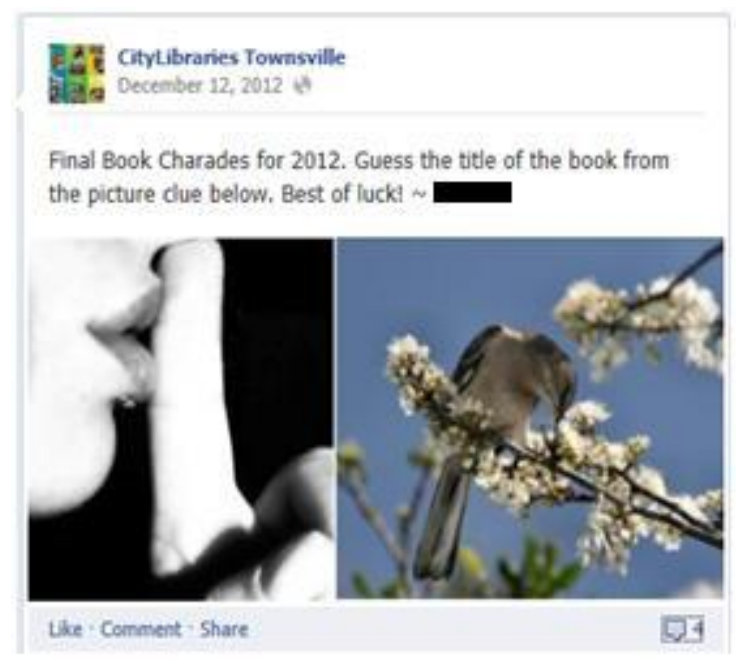

\section{Figure 6: Engagement post from CLT.}

Some of the engagement posts on the Facebook pages come from users posting on the wall and the library answering or commenting on their post. While the libraries' reply may be directed at only one user, it demonstrates that the library is 
willing to engage with users in this space, it can be viewed by anyone accessing the page, and it may impact on the likelihood of other users posting on the page. One library service that was monitored had not replied to comments left on its Facebook page and while it may have responded offline to the user, by not posting a public reply it could be losing an opportunity to demonstrate its commitment to and regard for users. Users that ask questions on social media usually want their reply on that channel; if they have posted a question on Facebook, they are looking for an answer on that channel, not via an email (King, 2012).

\subsection{Twitter}

In describing the power of Twitter for libraries, Gunton and Davis (2012) suggest that it should be seen as a tool that has three main roles: a service delivery and recovery channel, a site for community building and a site for information experience. Twitter was the second most used social media platform; 17 libraries including YPRL and CLT use it.

The majority of libraries observed tweeted far less than the recommended two to three times per day (Table 2).

\begin{tabular}{|l|l|l|l|l|}
\hline Library & Average tweets & & Library & Average tweets \\
\hline Lib m & 3.1 & & Lib d & 0.5 \\
\hline Lib e & 1.5 & Lib t & 0.4 \\
\hline Lib i & 1.3 & Lib f & 0.4 \\
\hline Lib h & 1.3 & Lib x & 0.2 \\
\hline Lib w & 1.1 & Lib a & 0.1 \\
\hline Lib j & 0.9 & Lib c & 0.02 \\
\hline YPRL & 0.7 & & Lib k & 0 \\
\hline Lib n & 0.7 & & Lib s & 0 \\
\hline CLT & 0.6 & & & \\
\hline
\end{tabular}

Table 2: Average tweets per day.

To ensure the success of a Twitter account, libraries must tweet regularly (two to three times per day) and ensure the account is used for engagement (Cahill, 2011; Tagtmeier, 2010; Fields, 2010; Loudon and Hall, 2010; King and Willen Brown, 2009; Steiner, 2009; Stuart, 2010; Fitcher, 2007).

\section{Broadcast}

Interestingly, libraries with the highest broadcast rate (over 40\%) included those that tweeted the most, (libraries M and I) and those that tweeted the least (libraries A and C). Libraries $\mathrm{M}$ and I are using Twitter to do more than broadcast, but realise there are also benefits to broadcasting. Libraries $\mathrm{A}$ and $\mathrm{C}$ seem to have used Twitter as a promotional afterthought, with messages that were not tailored to the platform being sent as advertising. Comparatively, YPRL and CLT had broadcast rates of around $20 \%$, showing that they are using the platform in a variety of ways, but they realise that it can have impact as a broadcast channel. 


\section{Information sharing / Information sharing to engagement}

Twitter had low information sharing to engagement rates across most libraries. This may be due to the fact that libraries' Twitter content is not tailored for the channel. Many libraries push content that is posted to other sites, such as Facebook, out via their Twitter account, using tools that automatically tweet new content in these other channels. This content may not always make sense in the Twitter format of 140 characters, making it more likely for users to ignore it. It may also be the result of not using the service often enough to engage with users. Twitter is used "in the moment" and users generally only see a limited history of posts when they log in. As such, if libraries only tweet once per day or less, then they may miss many of their users who are not logged on when the tweet is sent out. Only YPRL, CLT and three other libraries were able to achieve information sharing to engagement levels of $25 \%$ or above, indicating they had found an appealing voice on Twitter that their users responded to well.

\section{Engagement}

Engagement tweets were very low across all the libraries observed. YPRL and CLT had levels around $15 \%$ for engagement tweets, something only one other library achieved.

Twitter can be used as a channel for reference service provision, which CLT has done. CLT's innovative use of Twitter for reference service provision sees them take a pro-active approach to fielding enquiries. They use saved searches to see what is being tweeted about Townsville and, if appropriate, they will respond to provide an answer. In this way, they engage users in a similar manner to the engagement that occurs at a physical reference desk.

Often questions that people used to ask at the library are now being sent out on social media as a general question to a user's network. If the library is part of user's networks then there is more chance of the library engaging them. Pro-active searching of Twitter has allowed CLT to tap into these networks and make use of their resources, especially their local history collection.

@TownsvilleLib: @ @F_ @ @ Townsville \& best wishes for the gig! If you need local info, pls let us know

\section{Figure 7: CLT sending out a pro-active tweet in response to a tweet mentioning Townsville.}

CLT also followed local tweeters and found this beneficial. By responding to their tweets they have signed up new members who have gone on to tweet about the library's resources. While this is not a common occurrence, it demonstrates the impact that successful Twitter interactions can have.

\subsection{Blogs}

YPRL has 17 blogs across the library website, encompassing individual staff member blogs, branch blogs, local history and news and promotion. Seven of the other libraries monitored used blogs as well, but not CLT. Of the 17 YPRL blogs 
there were three that posted no new content during the ten week monitoring period and all had very low rates of posting overall. This was also the trend across the other seven libraries that used blogs. The highest posting was from a library that had no other social media presence. This service also did not have comments enabled on their blog so could not facilitate engagement or create conversation, which is arguably the main point of social media (King and Willen Brown, 2009).

Across all blogs there was an extremely low rate of commenting. During the observation period, only two libraries received any comments. This reflects the findings from other studies in the United States and New Zealand (Oguz and Holt, 2011; Rutherford, 2008b).

Sourcing content for blog posts can be difficult, particularly when low levels of customer engagement cause staff to question the value of blogging. Indeed, CLT believes blogs are an inefficient use of staff time as "all the information you would spend time putting into a blog is out there already so we can more valuably as library staff point to those places" according to one participant in the wider research project. YPRL's blogs include high quality posts aimed at engaging customers, yet they do not attract comments. This suggests that it is not the content of the blog that is the issue, rather it is the medium. This is demonstrated by a post that received no comments on a blog, but many as a Facebook post.
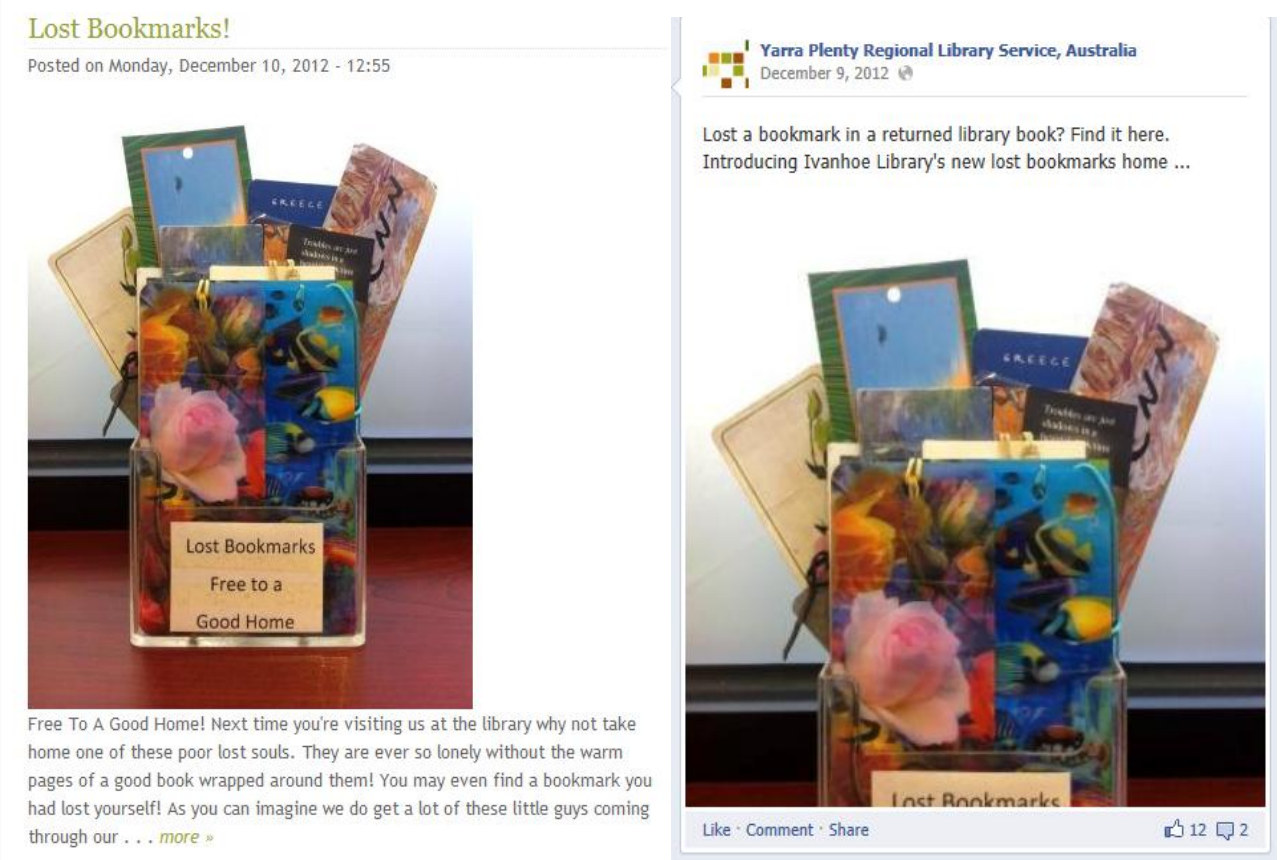

Figure 8: The same content on a blog and Facebook.

\section{$4.4 \quad$ YouTube}

In total, five of the 26 libraries have a YouTube presence, including YPRL, making it the least used social media tool. Of the four library services that are currently using YouTube only two posted any new content during the monitoring period. While the rate of posting was low, the rate of engagement was high. Across the five library services, four videos were uploaded in the observation period, and all of these received multiple comments. 
As YouTube is a social tool it is important to engage with users, respond to comments and allow them to become content creators (Colburn and Haines, 2012). CLT and YPRL have recognised the potential that YouTube has for engaging users, having conversations, and allowing users to become content creators (Stephens, 2007). Both identified it as a channel they would like to develop.

\subsection{Flickr}

YPRL and 14 of the other libraries observed have Flickr accounts, while CLT does not. This high uptake of Flickr is not reflected in the volume of uploads. Only three libraries (including YPRL) made use of their accounts to upload photos during the monitoring period. All the photos uploaded by the libraries were viewed multiple times, but none had received any comments by the end of the monitoring period. Of the 11 other services that did not upload to Flickr during the observation, four had not used their account in the past year and three had joined Flickr but never uploaded any photos or joined any groups.

Those libraries that uploaded photos mainly contributed photos of library events, exhibitions, competitions and renovations - essentially, photos that market the library. It has been suggested that public libraries can use Flickr to create engagement with their community by allowing them to contextualize photos with their own comments and stories (Forsyth, 2010), however, this did not seem to be happening during the observation period.

Of the 15 libraries using Flickr only one library had connections to groups or contacts in their local community, indicating the social aspect of the tool was not being exploited. Online communities tend to form around interests, such as hobbies or the local community or hometown, and Flickr offers public libraries the chance to connect with these online communities in a meaningful way (Farkas, 2007; Cahill, 2009). By contributing to groups, libraries can start a conversation, as opposed to simply pushing information out (Forsyth, 2010). By allowing users to add tags to the library's images, users become curators and descriptive cataloguers and in this way contribute to the development of a virtual collection. In turn, libraries become part of the community and appear human and approachable (Casey and Savastinuk, 2007).

Flickr can also be used as a way to identify materials for addition to the collection. The National Library of Australia, for example, has a formal, organisational presence on Flickr, but CLT have demonstrated that this might not be necessary. CLT uses Flickr to source images for their local history collection, but they do not have a Flickr account. After Cyclone Yasi, CLT's local history staff used Flickr to source photos for addition to the collection, as there was a huge amount of content already there. CLT staff emailed the users who had posted relevant photos and asked them for permission to add their images to the local history collection, with an overwhelmingly positive response. This allowed them to expand their collection via community knowledge.

Flickr can be a very powerful and engaging tool if libraries are prepared to invest the time to create connections and post images in a strategic way, taking the time 
to develop relationships and post images which are appealing and that will create engagement.

\subsection{Pinterest}

Libraries are using Pinterest to do many different things, from collating ideas for storytime craft activities to creating boards of books and resources that may appeal to specific groups (McDermott, 2012). YRPL, CLT and five of the other 24 libraries observed use Pinterest.

Like Flickr, Pinterest is a platform which lends itself to both serendipitous discovery of library pins and creating a following among users. Of the libraries that use Pinterest, YPRL have the largest number of followers, they follow more users than the other libraries, and have more pins (Figure 8).

YPRL are very considered when deciding what to post. They use Pinterest to create an online collection based on Dewey decimal numbers. The idea behind this is that creating a collection related to a subject area, such as recipes, is more appealing to users and will generate more re-pins and followers than pinning the bookcover of the latest novel.

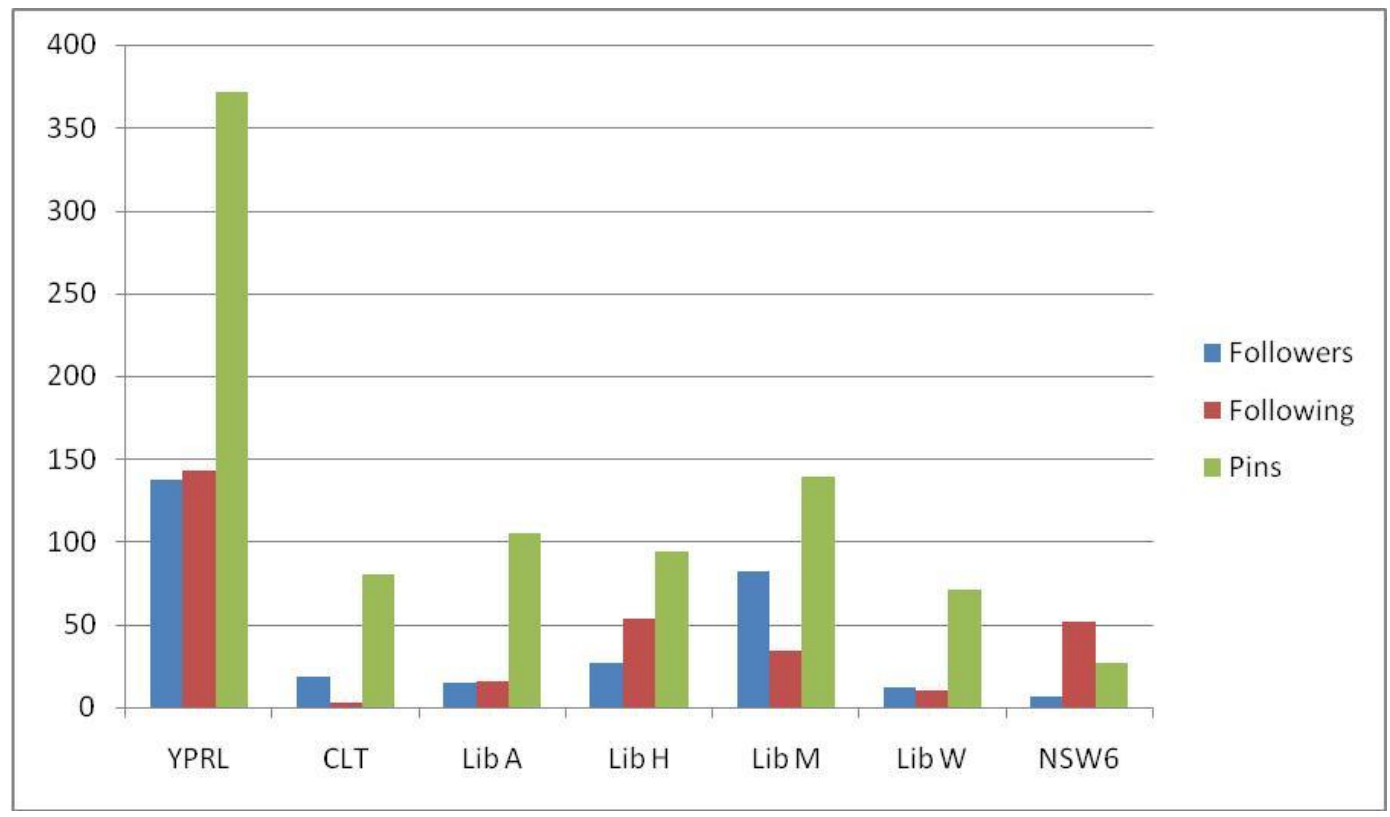

Figure 8: Pinterest usage among the libraries during observation.

This innovative use of Pinterest is obviously one that has engaged users, by curating content and creating collections that will be of interest, rather than presenting them with lists of resources. 


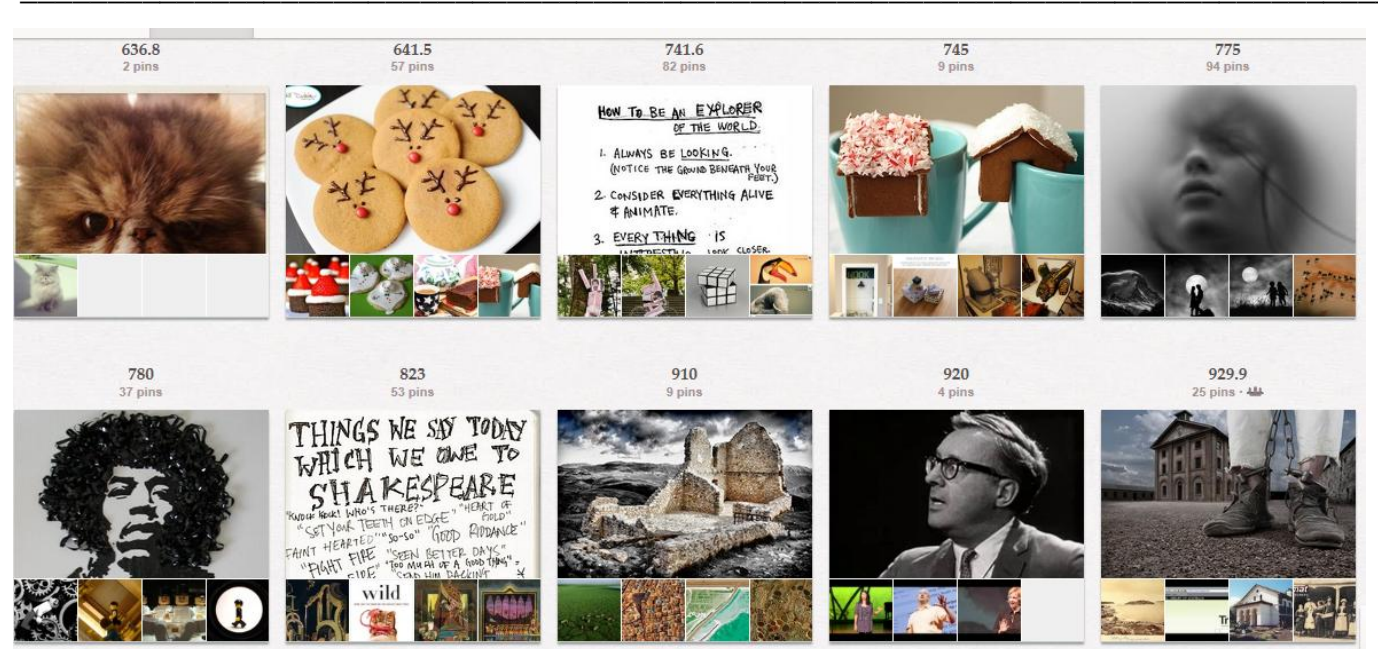

Figure 9: Section of YPRL's Pinterest page.

CLT and the other libraries on Pinterest are using the tool as a way to create lists of books, such as bookclub titles, staff recommendations or to pin photos from events. This use of Pinterest may not be as appealing to users because they are using the tool as a collection of images, like a Flickr account, rather than a content curation tool as YPRL are doing.

Pinterest has a very strong possibility for serendipitous discovery and by connecting with users who may never have looked at the library in any other arena the library can draw users into the library's collection or website (McDermott, 2012). As Pinterest is a relatively new social media tool its usefulness is still being explored by libraries, but it has enormous potential, particularly as a tool with which to target specific user groups (McDermott, 2012).

\section{Discussion}

To create a participatory library, social media needs to be used strategically, with a clear goal of engaging with users and using their knowledge to help develop a service that remains relevant to the community (Lankes, 2011). Aside from having a strategic goal, libraries also need to take into account best practice for each channel and understand how to use it well. In practical terms this means posting messages that are tailored to a particular channel, in terms of format, content and level of usage (King, 2012). On each channel the library needs to define a personality that will engage their users, making their voice unique and appealing through the content that they post, the relationships they develop and the way that they respond to their users in a particular space (King, 2012).

Social media allow libraries to create another entry point into the service for their users. By appealing to users on platforms on which they are already engaged users may be more inclined to use library services, for example users may not visit a library specific website, but will use a library Facebook page (Cahill, 2009). Overall, the results of the social media monitoring study appeared to show that Australian libraries have realised that it is necessary to have a presence on social media, but have focused on the utilisation of a tool rather than the wider benefits it could offer. This is where YPRL and CLT were able to set themselves apart from 
other libraries; by tailoring messages and focusing on user participation they appear to be focusing on the benefits that these tools can bring to a service.

Organisations that engage customers successfully tend to use social media in a thoughtful manner, with a well-defined persona designed to engage users, and content geared towards fostering engagement. YPRL, CLT and two other libraries were able to do this, but they were the exception rather than the rule.

The majority of the other libraries appeared to take a more haphazard approach to their social media accounts, posting less frequently and without seeming to have the clear aims in their use of social media.

To derive the most benefit from social media accounts they must be treated as engagement tools and used to create relationship with users. While amassing followers and likes is one way to measure this, examining the number of conversations that take place on each platform is another. Facebook is a tool that users are engaged and where they seem willing to interact with libraries. While much of the interaction is passive, running competitions and inviting comments will attract users and allow the library to have a greater reach. YPRL and CLT have shown that a successful Facebook page needs to be updated regularly and have an informal tone.

To use Twitter for engagement it needs to be given more attention. Setting up searches, proactively answering questions and following users are all ways to create conversations via Twitter and invite users to participate in helping to shape library services as well as becoming part of their social network. It also must be updated more frequently than other social media tools due so that users do not miss library content in their feeds.

Currently, blogs are used to a limited extent by libraries and do not seem to generate comments or interaction, but this seems to be more of an issue with the medium of blogging, rather than the way that they are using the tool, a finding reflected by other studies (Rutherford, 2008b; McLean, 2008; Oguz and Holt, 2007). Other social media tools across all libraries generated much higher engagement levels than blogs, which may indicate that library blogs are becoming redundant (Helgren and Lietzau, 2011).

Flickr and Pinterest are platforms that need to have a clear purpose to be of use to an organisation. Simply posting pictures of new resources or events does not generate interaction. By taking a more strategic approach and defining the rationale behind a Flickr set or a Pinterest board and making sure that it is either unique content, or content which has been uniquely curated, will attract users. At present it appears that many organisations are treating their organisational accounts the same way they would treat a personal photo album or board, randomly adding what appeals without considering their users.

YPRL and CLT seem to be leading the way in using social media as an engagement tool across the platforms that they use. YPRL is creating relationships with users and gaining followers across Twitter, Facebook, and Pinterest. CLT through their Flickr usage and Twitter account are trying to create and tap into community knowledge. If libraries are to develop relationships and become 
keepers of community knowledge then social media use needs to be more strategic (Chowdury et al., 2006).

At an operational level YPRL and CLT use social media very differently. YPRL has many different social media platforms and is happy to work across them all. In contrast CLT preferred to choose a few tools and concentrate on them. This has meant their accounts like Twitter and Facebook are very engaging for users. It has also allowed them to make innovative use of services like Flickr as they realise that having knowledge of a tool and knowing where to reach users or gather information can be just as powerful as an official library presence.

It was clear throughout the course of the monitoring that libraries are being contacted by their users via social media channels. If the attitude of the library staff is one where the account is seen as another broadcast channel then these interactions may be missed as the account is not being utilised effectively. Both CLT and YRPL were able to track all their engagements and respond to them, which is essential when monitoring a social media account. Once a person has become committed to social network site they tend to stay there and to make sure that they are staying in their users preferred spaces library services need to make sure they are committed to their desired social media space (Tagtmeier, 2010).

\section{Conclusion}

While this research focused on public libraries, the findings are applicable to libraries in other contexts and for any organisation looking to engage with its users via social media. Social media is a rapidly developing space. As more people grow up immersed in social media, it will become even more important for libraries to be present in these spaces. But it is not enough to be present. Libraries need to engage with social media thoughtfully, with a focus on developing their brand on existing channels and exploring new spaces. The two organisations that were the subject of this case study based project, YPRL and CLT, are leading the way in best practice for a participatory library service in Australian public libraries (Smeaton and Davis, 2014). Indeed, their practice meets what is considered to be best practice on an international level. Their approaches to social media are effective and other organisations may wish to look at the way they use their accounts to inform their own practice.

\section{References}

ALIA (2010) National Vision and Framework 2010-2015 [online]. URL: http://www.alia.org.au/sites/default/files/documents/advocacy/NationalVisionand Framework.pdf [accessed 6.7.2013].

Aharony, N. (2012) Facebook use in libraries: an exploratory analysis, Aslib Proceedings, 64(4) 358-372.

Bertot, J.C. and McClure, C. (2008) The impacts of free public internet access on public library patrons and communities, The Library Quarterly, 78(3), 285-301. 
Breeding, M. (2010) Taking the social web to the next level. The Systems Librarian, September, 28-30.

Cahill, K. (2009) User-generated content and its impact on web-based library services. Oxford: Chandos Publishing.

Cahill, K. (2011) Going social at Vancouver Public Library: what the virtual branch did next, Program: electronic library and information systems, 45(3), 259 $-278$.

Casey, M. and Savastinuk (2006) Library 2.0: Service for the next-generation library, Library Journal, 131(14), 40-44.

Casey, M. and Savastinuk, L. (2007) Library 2.0:A guide to participatory library service. Medford, NJ: Information Today Inc.

Chase, D. (2007) Transformative Sharing with Instant Messaging, Wikis, Interactive Maps, and Flickr, Computers in Libraries, 27(1), 6-8.

Chowdury,G., Poulter, A. and McMenemy, D. (2006) Public Library 2.0: Towards a new mission for public libraries as a "network of community knowledge", Online Information Review, 30(4), 454-460.

Colburn, S. and Haines, L (2012) Measuring libraries use of YouTube as a promotional tool: an exploratory study and proposed best practices, Journal of Web Librarianship, 6, 5-31.

Cowling, D. (2013) Social media statistics Australia -June 2013 [online]. URL: http://www.socialmedianews.com.au/social-media-statistics-australia-june-2013/ [accessed 7.7.2013]

Farkas, M. (2007) Social software in libraries: Building collaboration, communication and community online. Medford, NJ: Information Today Inc.

Fernandez, J. (2009) A SWOT analysis for social media in libraries, Online, 3537. URL: http://www.infotoday.com/online/default.shtml [accessed 7.10.2012].

Fields, E. (2010) A unique Twitter use for reference services, Library Hi Tech News, 27 (6), 14-15.

Fichter, D. (2006) Web 2.0, Library 2.0 and radical trust: a first take. URL: http://library2.usask.ca/ fichter/blog_on the side/2006/04/web-2.html [accessed 12.10.2012].

Fitcher (2007) How social is your website? Top five tips for social media optimization, Online, 31(3), 57-60.

Forsyth, E. (2010) Picturing your community: Flickr use in public libraries, Library Hi Tech News, 27(1), 6-9.

Gunton, L. and Davis, K. (2012) Beyond broadcasting: customer service, community and information experience in the Twittersphere, Reference Services Review, 40(2), 224-227.

Helgren, J. and Lietzau, Z. (2011) U.S. public libraries and web technologies, Computers in Libraries, 31(7), 12-16. 
Joint, N. (2010) Web 2.0 and the library: a transformational technology? Library Review, 59 (7), 490-497.

King, D.L. (2011) Facebook for libraries, American Libraries Magazine, 43, 4245

King, D.L. (2012) Social Media. Library Technology Reports, 48(6), 23-27.

King, D.L. and Willen Brown, S. (2009) Emerging Trends, 2.0, and Libraries, The Serials Librarian, 56, 32-43.

Kwanya, T. G., Stilwell, C. and Underwood, P.G. (2009) Library 2.0: revolution or evolution? South African Journal Of Library \& Information Science, 75, 70-75.

Lankes, R.D. (2011) The Atlas of New Librarianship. Cambridge, MA: The MIT Press.

Lankes, R. D., Silverstein, J., Nicholson, S., and Marshall, T. (2007), Participatory networks: the library as conversation, Information Technology and Libraries, 12(4), 17-33.

Loudon, L. and Hall, H. (2010) From triviality to business tool: The case of Twitter in library and information services delivery, Business Information Review, 27, 236-241.

Manness, J. M. (2006) Library 2.0 theory: Web 2.0 and its implications for libraries, Webology [online], 3(2). URL: http://webology.ir/2006/v3n2/a25.html [accessed 8.10.2012].

McDermott, I. (2012) Pinterest for libraries, Searcher, 20(4), 7-9.

McLean, M. (2008) Virtual services on the edge: Innovative use of web tools in public libraries, Australian Library Journal, 57(4), 431-451.

Mc Shane, I. (2011) Public libraries, digital literacy and participatory culture, Discourse: Studies in the Cultural Politics of Education, 32 (3), 383-397.

Nguyen, L.C., Partridge, H. and Edwards, S.L. (2012) Towards an Understanding of the Participatory Library, Library Hi Tech, 30 (2) 335-346.

Norman, M. (2012) Frail, fatal, fundamental: the future of public libraries, Australasian Public Libraries \& Information Services, 25(2), 94-100.

Oguz, F. and Holt, M. (2011) Library blogs and user participation: A survey about comment spam in library blogs, Library Hi Tech, 29(1), 173-188.

Porter, M. and King, D. (2007) Inviting Participation, Public Libraries, 46 (6), 3436.

Prentice, A. (2010). Public Libraries in the 21st Century. Westport: Libraries Unlimited.

Rooney-Browne, C. and McMenemy, D. (2010) Public libraries as impartial spaces in a consumer society: possible, plausible, desirable? New Library World, 111(11), 455-467.

Rutherford, L. (2008a) Building participative library services: the impact of social software use in public libraries, Library Hi Tech, 26(3), 411-423. 
Rutherford, L. L. (2008b) Implementing social software in public libraries. Library Hi Tech, 26(2), 184-200.

Smeaton, K. and Davis, K. (2014) Social technologies in public libraries: exploring best practice, Library Management, 35(3), 224-238.

Steiner, H. (2009) Reference utility of social networking sites: Options and functionality, Library Hi Tech News, 26(5), 4-6.

Stuart, D. (2010) What are libraries doing on twitter? Online, 34(1), 45-47.

Stephens, M. (2007) Social video: Videoblogging and YouTube, Library Technology Reports, 43(5), 52-57.

Tagtmeier, C. (2010) Facebook vs. twitter: Battle of the social network stars. Computers in Libraries, 30(7), 6-10.

Tarulli, L. (2012) The Library Catalogue as a Social Space. Santa Barbara: Libraries Unlimited.

Townsville City Council (2010) City Profile and Statistics [online]. URL: http://www.townsville.qld.gov.au/townsville/cityprofile/Pages/default.aspx [accessed 27.7.2013].

Waller, V. (2008) Legitimacy for large public libraries in the digital age, Library Review, 57(5), 372-385.

Yarra Plenty Regional Library (2008) Yarra Plenty Regional Library Strategic Plan 2008-2012 [online]. URL:

http://filestore.yprl.vic.gov.au/Library Plan/YPRL-Strategic-Library-Plan-20082012.pdf [accessed 27.07.2013].

\section{Acknowledgement}

All images are reproduced with the permission of Yarra Plenty Regional Libraries and City Libraries Townsville.

\section{Open access and copyright}

Library and Information Research is an open access journal. A freely available copy of this paper may be downloaded from the journal's website: http://www.lirgjournal.org.uk.

Copyright and associated moral rights in works published in Library and Information Research are retained by the author(s) but this paper may be used freely, with proper attribution, in educational and other non-commercial settings. 